http://jmscr.igmpublication.org/home/ ISSN (e)-2347-176x ISSN (p) 2455-0450 crossref DOI: https://dx.doi.org/10.18535/jmscr/v8i4.14

\title{
Appraisal of Patient Safety Culture in a Tertiary Care Hospital from North India
}

\author{
Authors \\ Dr Ennas Chowdhary ${ }^{*}$, Dr Farooq A Jan ${ }^{2}$ \\ ${ }^{1}$ Senior Resident, Department of Hospital Administration SKIMS Srinagar \\ ${ }^{2}$ Professor, Department of Hospital Administration \& Medical Superintendent SKIMS Srinagar \\ *Corresponding Author \\ Dr Ennas Chowdhary \\ Senior Resident Hospital Administration, SKIMS Srinagar, India
}

\begin{abstract}
Background: Patient Safety is critical component of health care quality. We aimed to study the patient safety culture among healthcare providers.

Methodology: A prospective questionnaire was carried out for a period of one year in inpatient area, ICU's, OT's and Emergency department. Doctors, nurses and technicians were the subjects of study. Agency of Healthcare research and quality (AHRQ) patient safety culture questionnaire was used as a study tool.

Results: The dimension teamwork within department scored the highest positive response of $77.3 \%$ and organizational learning -continuous improvement scored the second highest positive response of $76.1 \%$ while as staffing scored the lowest response of 34.6\%. $42.8 \%$ of the participants rated dimension patient safety grade in their work unit as very good and 84.5\% of the participants reported no events in the last 12 months.

Conclusion: There is high spirit of teamwork within the units however healthcare providers are overworked due to shortage of staff.

Keywords: Patient Safety, Patient safety culture, $A H R Q$.
\end{abstract}

\section{Introduction}

Patient safety culture is defined as "the product of individual and group values, attitudes, perceptions, competencies and patterns of behaviour that determine the commitment to and the style and proficiency of an organizations safety management". ${ }^{(1,2)}$

Reducing medical errors has become an international concern. Population-based studies from a number of nations around the world have consistently demonstrated unacceptably high rates of medical injury and preventable deaths. In response, a global effort, the World Alliance for patient safety, has been launched by WHO to galvanize and facilitate efforts by all member states to make health care safer. ${ }^{(3)}$

Patient Safety is critical component of health care quality. As health care organization continually shine to improve there is a growing recognition of the importance of establishing a culture of safety. Achieving a culture of safety requires an understanding of the values, beliefs and norms about what is important in an organization and what attitudes and behaviours related to patient safety are expected and appropriate. ${ }^{(4)}$ 
The concept of safety culture originated outside health care, in studies of high reliability organizations, organizations that consistently minimize adverse events despite carrying out intrinsically complex and hazardous work. High reliability organizations maintain a commitment to safety at all levels, from frontline providers to managers and executives. This commitment establishes a "culture of safety "that encompass these key features:

- Acknowledgement of high-risk nature of an organizations activities and the determination to achieve consistently safe operations

- A blame-free environment where individuals are able to report errors or near misses without fear of reprimand or punishment

- Encouragement of collaboration across ranks and disciplines to seek solutions to patient safety problems

- Organizational commitment of resources to address safety concerns ${ }^{(5)}$

\section{Methods}

A prospective study was done for a period of 1 year in inpatient area, ICU's, OT's and Emergency department

Study Population: It includes doctors, nurses and technical staff working in the above selected areas were subjects of study.

Study Tool: AHRQ Hospital Survey Patient Safety Culture Questionnaire adapted from Agency of Healthcare research and Quality was used as a study tool ${ }^{(6)}$. Pilot study was carried out for a period of two weeks to validate the tool and later on it became the part of observations.

AHRQ Hospital survey patient safety culture questionnaire has 42 items similar items were clubbed together under headings of 12 dimensions ${ }^{(7)}$;

Teamwork within departments, Organizational Learning- continuous improvement, Overall perception of safety, Non-punitive response to error, Staffing, Supervisor/Manager expectations and actions promoting patient safety, Communication Openness, Feedback and Communication about error, Frequency of events reported, Hospital management support for patient safety, Teamwork across hospital departments, Hospital handoffs and transitions

Responses regarding various aspects of patient safety culture were graded on a five point LIKERT scale (Strongly disagree, disagree, neither, agree, strongly agree /Never, rarely, sometimes, most of the time, always). For each positively worded item, the percentage of positive responses were calculated i.e. the percentage of participants answering the question as strongly agree and agree or sometimes, always or most of the time. Negatively worded items were reverse coded $(\mathbf{R})$, so for all questions higher scores are more favourable.

The dimension Patient safety was graded as excellent, very good, acceptable, poor and falling. The number of events reported were documented as per event reports in the past 12 months: no event reports, 1 to 2 event reports, 3 to 5 event reports, 6 to 10 event reports and 21 event reports/more.

The researcher visited the selected areas on daily basis and presented the questionnaire to the study population .The time period of 7 days had been given to each subject to return the questionnaire. Those study subjects who did not return the questionnaire were excluded from the study .Incomplete replies (Forms which were kept partially blank) to questionnaires were also excluded from the study.

\section{Statistical Analysis}

All the statistical analysis was done by using SPSS software V23. All the categorical variables were shown in the form of frequency and percentage.

\section{Results}

Out of total 915 study subjects 780 participants responded to Agency of Healthcare research and Quality (AHRQ) adapted Hospital Survey patient 
safety culture questionnaire giving a response rate of $85.2 \%$.

It was observed that out of 780 participants majority $56.4 \%(n=440)$ were doctors, 307 were nurses and 33 were technicians. It was found that dimension teamwork within departments scored the highest percentage positive response of $77.3 \%$ with the mean positive value of 3.09. The dimension organizational Learning - continuous improvement scored the next highest percentage positive response of $76.1 \%$ with the mean positive value of 2.28. Staffing scored the lowest percentage positive response of $34.6 \%$ with the mean positive value of 1.39.(Table 1)
It was observed that $42.8 \%$ of the participants rated dimension patient safety grade in their work unit as very good, $38.2 \%$ rated patient safety grade in their work unit as acceptable, $13.8 \%$ rated patient safety grade as excellent, $4.1 \%$ rated poor and only $1 \%$ rated patient safety grade as falling. (Figure 1).

Observations revealed that $84.5 \%$ of the participants reported no events in the last 12 months, $10.3 \%$ reported only 1 to 2 events, $4.2 \%$ reported 3 to 5 events, $0.9 \%$ reported $6-10$ events while as only $0.1 \%$ reported $11-20$ events. (Figure 2).

Table 1: Patient safety culture dimensions viz- a -viz positive response

\begin{tabular}{|c|c|c|}
\hline Items of Patient safety culture dimensions & $\begin{array}{l}\text { Percentage Positive } \\
\text { response }\end{array}$ & $\begin{array}{l}\text { Mean Positive } \\
\text { values }\end{array}$ \\
\hline Teamwork within departments(AA1) & $77.3 \%$ & 3.09 \\
\hline People support one another in this unit. & $90.5 \%$ & 0.91 \\
\hline $\begin{array}{l}\text { When a lot of work needs to be done quickly, we work together as a team to get } \\
\text { the work done. }\end{array}$ & $84.6 \%$ & 0.85 \\
\hline In this unit, people treat each other with respect & $82.8 \%$ & 0.83 \\
\hline When one area in this unit gets really busy, others help out & $51.3 \%$ & 0.51 \\
\hline Organizational Learning - continuous improvement(AA2) & $76.1 \%$ & 2.28 \\
\hline We are actively doing things to improve patient safety & $89.4 \%$ & 0.89 \\
\hline Mistakes have led to positive change here. & $65.0 \%$ & 0.65 \\
\hline After we make changes to improve patient safety, we evaluate their effectiveness. & $74.0 \%$ & 0.74 \\
\hline Overall perception of safety & $60.5 \%$ & 2.42 \\
\hline Patient safety is never sacrificed to get more work done. & $72.1 \%$ & 0.72 \\
\hline Our procedures and systems are good at preventing errors from happening. & $62.3 \%$ & 0.62 \\
\hline It is just by chance that more serious mistakes don't happen around here $(\mathbf{R})$ & $55.6 \%$ & 0.56 \\
\hline We have patient safety problems in this unit.(R) & $51.9 \%$ & 0.52 \\
\hline Non-punitive response to error(AA4) & $45.7 \%$ & 1.37 \\
\hline Staff feel like their mistakes are held against them. (R) & $45.0 \%$ & 0.45 \\
\hline $\begin{array}{l}\text { When an event is reported, it feels like the person is being written up, not the } \\
\text { problem. (R) }\end{array}$ & $42.9 \%$ & 0.43 \\
\hline Staff worry that mistakes they make are kept in their personal file.(R) & $49.1 \%$ & 0.49 \\
\hline Staffing (AA5) & $34.6 \%$ & 1.39 \\
\hline We have enough staff to handle the workload. & $19.0 \%$ & 0.19 \\
\hline Staff in this unit work longer hours that is best for patient care. (R) & $30.3 \%$ & 0.30 \\
\hline We use more agency/temporary staff than is best for patient care. (R) & $65.8 \%$ & 0.66 \\
\hline We work in "crisis mode," trying to do too much, too quickly. (R) & $23.6 \%$ & 0.24 \\
\hline Supervisor/Manager expectations and actions promoting patient safety(B) & $62.8 \%$ & 2.51 \\
\hline $\begin{array}{l}\text { My supervisor/manager says a good word when he/she sees a job done according } \\
\text { to established patient safety procedures. }\end{array}$ & $72.9 \%$ & 0.73 \\
\hline $\begin{array}{l}\text { My supervisor/manager seriously considers staff suggestions for improving } \\
\text { patient safety }\end{array}$ & $67.4 \%$ & 0.67 \\
\hline $\begin{array}{l}\text { Whenever pressure builds up, my supervisor/ manager wants us to work faster, } \\
\text { even if it means taking shortcuts. (R) }\end{array}$ & $57.1 \%$ & 0.57 \\
\hline $\begin{array}{l}\text { My supervisor/manager overlooks patient safety problems that happen over and } \\
\text { over. (R) }\end{array}$ & $53.7 \%$ & 0.54 \\
\hline Communication Openness(CC1) & $62.1 \%$ & 1.86 \\
\hline $\begin{array}{l}\text { Staff will freely speak up if they see something that may negatively affect patient } \\
\text { care. }\end{array}$ & $80.0 \%$ & 0.80 \\
\hline
\end{tabular}


Staff feel free to question the decisions or actions of those with more authority

Staff are afraid to ask questions when something does not seem right.(R)

Feedback and Communication about error(CC2)

We are given feedback about changes put into place based on event reports.

We are informed about errors that happen in this unit.

In this unit, we discuss ways to prevent errors from happening again.

Frequency of events reported(D)

When a mistake is made, but is caught and corrected before affecting the patient,

how often is this reported?

When a mistake is made, but has no potential to harm the patient, how often is

this reported?

When a mistake is made that could harm the patient, but does not, how often is this reported?

\begin{tabular}{|c|c|c|}
\hline Hospital management support for patient safety (FF1) & $66.1 \%$ & 1.98 \\
\hline Hospital management provides a work climate that promotes patient safety. & $69.6 \%$ & 0.70 \\
\hline The actions of hospital management show that patient safety is a top priority. & $72.1 \%$ & 0.72 \\
\hline $\begin{array}{l}\text { Hospital management seems interested in patient safety only after an adverse } \\
\text { event happens. (R) }\end{array}$ & $56.5 \%$ & 0.57 \\
\hline Teamwork across hospital departments(FF2) & $67.9 \%$ & 2.72 \\
\hline There is good cooperation among hospitals units that need to work together. & $62.6 \%$ & 0.63 \\
\hline Hospital units work well together to provide the best care for patients. & $73.2 \%$ & 0.73 \\
\hline Hospital departments do not coordinate well with each other. $(\mathbf{R})$ & $61.2 \%$ & 0.61 \\
\hline It is often unpleasant to work with staff from other hospital units.(R) & $74.9 \%$ & 0.75 \\
\hline Hospital handoffs and transitions(FF3) & $49.3 \%$ & 1.97 \\
\hline $\begin{array}{l}\text { Things "fall between the cracks"' when transferring patients from one unit to } \\
\text { another.(R) }\end{array}$ & $45.8 \%$ & 0.45 \\
\hline Important patient care information is often lost during shift changes.(R) & $67.7 \%$ & 0.68 \\
\hline Problems often occur in the exchange of information across hospital units.(R) & $47.3 \%$ & 0.47 \\
\hline Shift changes are problematic for patients in this hospital.(R) & $36.4 \%$ & 0.36 \\
\hline
\end{tabular}

*Note: *For each positively worded item, the percentage of positive responses was calculated- i.e. the percentage of participants answering the question as strongly agree and agree or sometimes, always or most of the time. Negatively worded items are reverse coded (R), so for all questions higher scores are more favourable

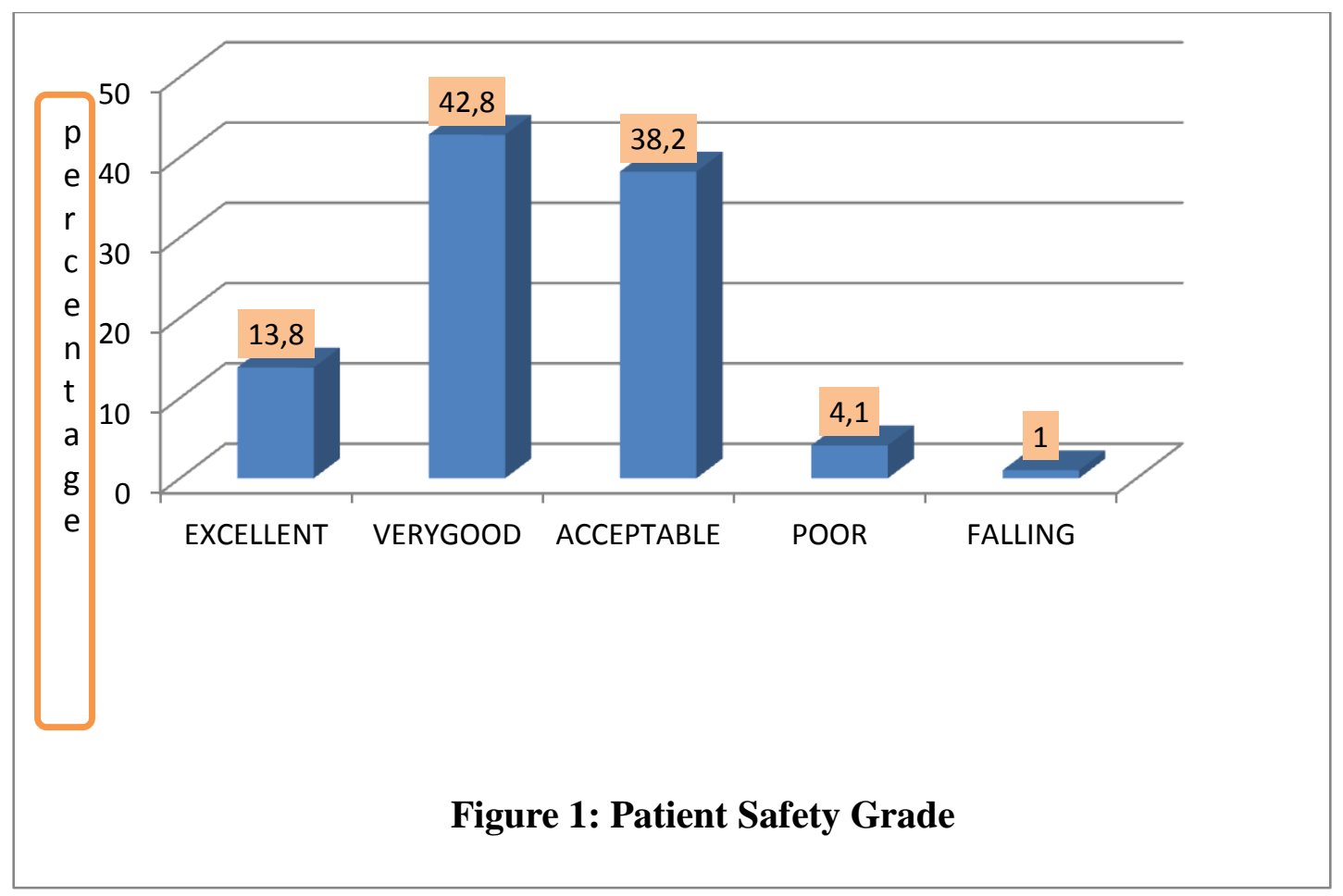




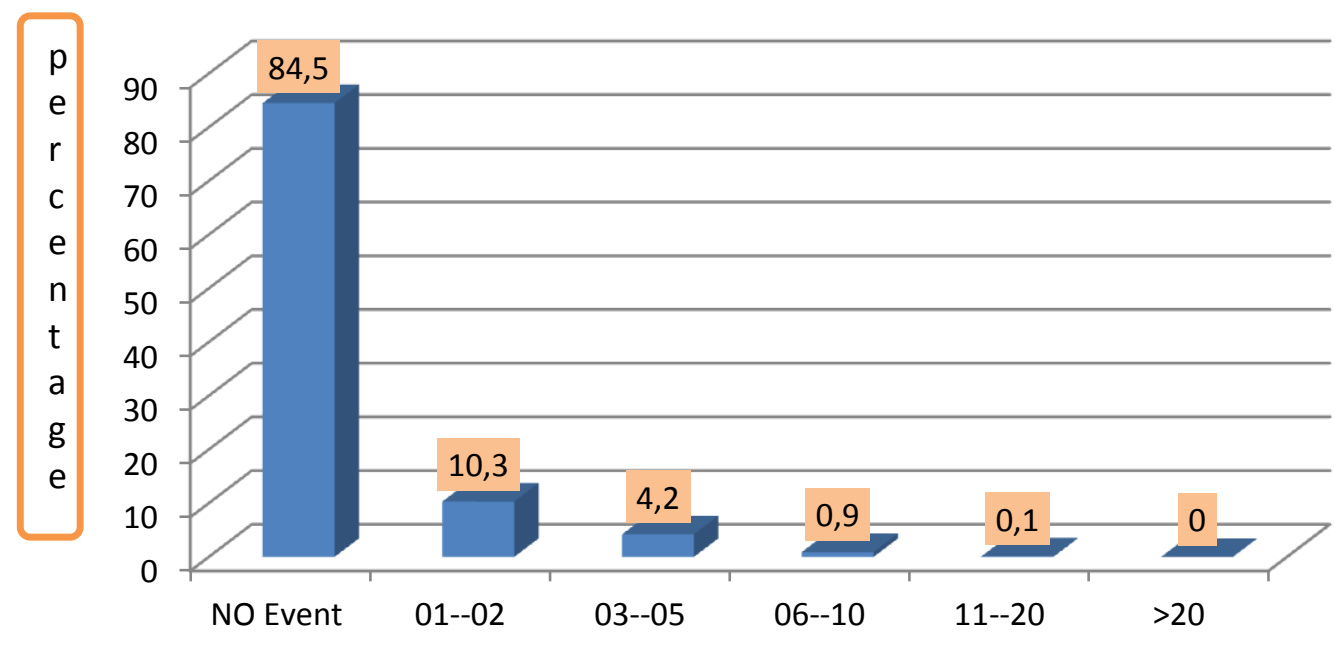

Figure 2: No of Events Reported

\section{Discussion}

Increasingly, healthcare organizations are becoming aware of the importance of transforming organizational culture in order to improve patient safety. Growing interest in safety culture has been accompanied by the need for assessment tools focused on the cultural aspects of patient safety improvement efforts. ${ }^{(8)}$

Current study revealed teamwork within departments scored the highest percentage positive response of $77.3 \%$. Its highest score indicates unity and coordination among all units. Teamwork within departments form an important component to achieve organizational goals. This finding is consistent with the study carried out by Sorra $\mathrm{J}$ et al which showed that the dimension teamwork within departments received the highest percentage positive response of $79 \%{ }^{(9)}$. In line with the current study Hellings $\mathrm{J}$ et al conducted a study which showed that the dimension teamwork within departments generated the highest score of $70 \%$. $^{(10)}$

The next highest positive response in our study is for the dimension organizational learning continuous improvement (76.1\%). High positivity score is indicating that health care providers are learning from their mistakes and from CME programs thereby making them perfect which in turn helps in improving patient safety. This finding is in accordance with the study carried out by Amarapathy $\mathrm{M}$ et al where the dimension organizational learning -continuous improvement scored the next highest positive response of $82.5 \%$ however the score was higher than that of current study ${ }^{(11)}$. Chen IC et al showed that the dimension organizational learning -continuous improvement received the next highest positive response of $84 \%$ however the score was higher than that of current study ${ }^{(12)}$. Nie Y et al conducted study on Hospital Survey on patient safety culture where it was observed that organizational learning -continuous improvement received the highest percentage positive response of $88 \%$. This finding is contrary to what was observed in the current study ${ }^{(13)}$. Ghobashi MM et al showed that organizational learning -continuous improvement scored the highest percentage positive response of $75 \% .^{(14)}$

In the current study the dimension that had the lowest percentage of positive response was staffing $(34.6 \%)$. Lowest percentage refers to inadequate manpower strength thereby affecting patient care. Study carried out by Amarapathy M et al also showed that dimension that had received the lowest percentage positive response was 
staffing (15\%) however it was lower than that of the current study ${ }^{(11)}$. Hellings $\mathrm{J}$ et al observed that staffing scored the percentage positive response of $38 \%$ which is near to that of current study ${ }^{(10)}$. In line with the present study Moghri $\mathrm{J}$ et al showed that dimension staffing scored the positive response of $35 \%$. $^{(15)}$

Our study revealed overall perception of safety scored the percentage positive response of $60.5 \%$. In line with the present study Rajalatchumi et al also observed that overall perception of safety received the percentage positive response of $60.8 \%{ }^{(16)}$. Bodur $\mathrm{S}$ et al showed slightly similar pattern to current study in which overall perception of safety scored the positive response of $59 \%{ }^{(17)}$.

In the present study non-punitive response to error scored the positive response of $45.7 \%$ Contrary to this finding Nie $\mathrm{Y}$ et al showed that non-punitive response to error scored the percentage positive response of $60 \%{ }^{(13)}$.

Current study revealed that manager expectations and actions promoting safety scored the percentage positive response of $62.8 \%$. In line with the present study Nie $\mathrm{Y}$ et al observed that manager expectations and actions promoting safety received the percentage positive response of $63 \%{ }^{(13)}$. Contrary to the finding of current study Chen IC et al showed that the dimension manager expectations and actions promoting safety scored the percentage positive response of $83 \%$. ${ }^{(13)}$

In our study communication openness received the percentage positive score of $62.1 \%$. NieY et al also showed slightly similar pattern as that of present study in which it was analyzed that the dimension communication openness received the positive response of $65 \%{ }^{(22)}$. Contrary to this finding Moghri $\mathrm{J}$ et al observed that dimension communication openness scored the percentage positive response of $42 \%$. $^{(15)}$

In the current study feedback and communication about error scored the percentage positive response of $74.6 \%$. In contrary to this finding Chen IC et al showed that the dimension feedback and communication about error scored the percentage positive response of $59 \% .^{(12)}$

Present study revealed frequency of event reported received the positive response of $66.7 \%$.Contrary to this finding Amarapathy $\mathrm{M}$ et al carried out a study in which results showed that the dimension frequency of event reported scored $36.3 \%{ }^{(11)}$. Moghri J et al showed frequency of event reported received the percentage positive response of $46 \%$. $^{(15)}$

In our study hospital management support for patient safety received the percentage positive response of $66.1 \%$. Chen IC et al showed slightly similar pattern in which the dimension hospital management support for patient safety scored percentage positive response of $62 \%{ }^{(12)}$. Hellings $\mathbf{J}$ et al showed that hospital management support for patient safety scored the percentage positive response of $35 \%$ contrary to finding of the current study. ${ }^{(10)}$

The dimension teamwork across departments scored the percentage positive response of $67.9 \%$ in our study. In line with the current study Ghobashi $\mathrm{M}$ et al showed that teamwork across department scored $63 \%$ which is almost similar to that of present study. ${ }^{(14)}$

Current study revealed hospital handoffs and transitions received the percentage positive response of $49.3 \%$. Amarapathy $\mathrm{M}$ et al showed that hospital handoffs and transitions scored the percentage positive response of $74.6 \%$ contrary to finding of this study. ${ }^{(11)}$

In the present study dimension overall patient safety was graded as very good by maximum of the respondents $(42.8 \%)$. In line with present study Nie $\mathrm{Y}$ et al showed that overall perception of safety was graded as very good by maximum of respondents $(56 \%){ }^{(13)}$

In our study it was found that $84.5 \%$ of the participants reported no events in the last 12 months. It was probably because of fear of reporting and lack of any non-punitive reporting system in place. Rao MV et al showed that $47 \%$ of the participants reported no events. ${ }^{(18)}$ 


\section{Conclusion}

The study in conclusion established that there is high spirit of teamwork within the units however healthcare providers are overworked due to shortage of staff.

\section{Ethical Consideration}

An ethical approval was obtained from institutional ethical committee.

\section{References}

1. Flin R, Burns C, Mearns K, Yule S, Robertson E. Measuring safety climate in health care. Quality and Safety in Health Care, 2006; 109-115.

2. Frenzel. (2010). Patient Safety in European University Hospitals (Master Thesis).

3. WHO Draft Guidelines for Adverse Event Reporting and Learning Systems World Alliance for Patient Safety. World Health Organization 2005. WHO/EIP/SPO/QPS/05.3

http://www.who.int/patient safety /events/05/Reporting - Guidelines.pdf.

4. Agency for health care Research and Quality (AHRQ). Nursing home survey on patient safety culture. Background and information for Translators.2010. Available from http:// www.ahrq.govt legacy /qual/patient safety culture/ infotrans NHSOPS. Pdf (Accessed May 24, 2010)

5. Culture Safety/AHRQ Patient safety Network.

Psnet.ahrq.gov/primers/primer5.June 2017

6. Hospital survey on patient safety culture content last reviewed May 2016, Agency for Healthcare Research and Quality, Rockville, MD

http://

www.ahrq.gov/professionals/qualitypatient-safety/patient

7. Jones KJ, Skinner A, MS LX, Sun J, Mueller k. The AHRQ Hospital Survey on
Patient Safety Culture: A Tool to Plan and Evaluate Patient Safety Programs

8. Nieva, V.F. and Sorra, J., Safety culture assessment: a tool for improving patient safety in healthcare organizations, Qual. Saf Health Care, 12 Suppl 2 (2003) ii 17ii23.

9. Sorra J, Famolaro T, Dyer $\mathrm{N}$, et al. Hospital Survey on patient culture 2009 comparative database report. Rockville, MD: Agency for healthcare Research and Quality; March 2009. AHRQ Publication No. 09-0030.

10. Hellings J, Schrooten W, Klazinga N, Vleugels A. Challenging patient safety culture: survey results. International Journal of health care quality assurance, 2007; 20(7).

11. Amarapathy M, Sridharan S, Perera R, Handa Y, Factors Affecting Patient Safety Culture In A Tertiary Care Hospital In Sri Lanka, International Journal Of Scientific \& Technology Research 2 (2013)173-180.

12. Chen IC,Li HH.Measuring patient safety culture in Taiwan using the Hospital Survey on Patient Safety Culture (HSOPSC).BMC Health Service Research 2010:10:152.

13. Nie Y, Mao X, Cui H, He S, Li J and Zhang M. Hospital survey on patient safety Culture in China, Nie et al. BMC Health Services Research 2013, 13:228.

14. Ghobashi M M, Ghani El-ragehy HA, Mosleh H, Abdullah Al-Doseri F.Assessment of Patient Safety Culture in Primary Health Care Settings in Kuwait. Epidemiology Biostatistics and public health -2014, volume 11, number 3.

15. Moghri J, Nateghi E, Arab M, Moghri M, Sari A A, Omranikhoo H, Najjar AV, Azar FE. Measurement of Patient Safety Culture in Iranian hospitals: A National Baseline Study J Clin Res Gov 2 (2013)47-52.

16. Rajalatchumi A, Ravikumar TS, Muruganandham K, Thulasingam M, 
Selvaraj K, Reddy M M, Jayaraman B. Perception of Patient Safety Culture among Health- care Providers in a Tertiary Care Hospital, South India .J Nat Sci Biol Med.2018 Jan-Jun: 9(1): 14-18.

17. Bodur S, Filiz E.A Survey on patient safety culture in primary health care service in Turkey, International journal for Quality in health care 2009, volume 21,Number 5; pp.348-355.

18. Rao MV, Thota D, Srinivas P. A study to assess patient safety culture amongst a category of hospital staff of a teaching hospital. IOSR Journal of Dental and Medical Sciences. 2014 ;13(3). 